\title{
Comparative evaluation of efficacy and safety of primaquine sustained- release tablets v/s primaquine conventional tablets in Treatment and prevention of relapse of plasmodium vivax malaria
}

\author{
Vishnu Kumar Gupta ${ }^{1}$, Gopal Jhalani ${ }^{2}$, Harsh Yadav $^{3}$, Arvind Verma ${ }^{4}$, Shivankan Kakkar ${ }^{1}$
}

\author{
${ }^{1}$ Department of Medicine, NIMS \\ Medical College, Jaipur, \\ Rajasthan, India \\ ${ }^{2}$ Department of Pharmacology, \\ NIMS Medical College, Jaipur, \\ Rajasthan, India \\ ${ }^{3}$ Department of Pharmacology, \\ SMS Medical College, Jaipur, \\ Rajasthan, India \\ ${ }^{4}$ Department of Skin and V.D., \\ NIMS Medical College, Jaipur, \\ Rajasthan, India
}

Received: 07 October 2016

Accepted: 03 November 2016

*Correspondence to:

Dr. Vishnu Kumar Gupta,

Email: dr.vishnu2001@

gmail.com

Copyright: (C) the author(s), publisher and licensee Medip Academy. This is an openaccess article distributed under the terms of the Creative Commons Attribution NonCommercial License, which permits unrestricted noncommercial use, distribution, and reproduction in any medium, provided the original work is properly cited.

\begin{abstract}
Background: Malaria is one of the most important parasitic disease of human. In India $60-65 \%$ of infections are due to P.vivax and $35-40 \%$ are due to P.falciparum Malaria is an acute, recurrent and sometimes chronic vector borne protozoan disease which has worldwide distribution in tropical and subtropical regions The role of Primaquine is well established in the prevention of relapse of P.vivax malaria. Primaquine has a narrow therapeutic range and short halflife that requires daily administration upto 2 weeks, resulting in poor compliance
\end{abstract}

Methods: Randomized control trial, which involved 100 patients of P.vivax Malaria Patient in medical ward of mahatma Gandhi hospital attached to S N medical college 'Jodhpur. All patient in this study received chloroquine for 3 days (10mg of base per $\mathrm{kg}$ followed by $5 \mathrm{mg} / \mathrm{kg} 6-8$ hours later and $5 \mathrm{mg} / \mathrm{kg}$ on each of the two days, total $25 \mathrm{mg} / \mathrm{kg}$ over 3 days and divided in three groups viz.Group 1 taken Primaquine $15 \mathrm{mg}$ tab for 14 days $(\mathrm{n}=34)$, Group 2 taken Primaquine $15 \mathrm{mg}$ SR tab for 14 days (n=33), Group 3 taken Primaquine $30 \mathrm{mg}$ SR tab for 7 days and placebo for next 7 days.

Results: In this study, Efficacy and compliance of Primaquine $30 \mathrm{mg}$ SR for 7 days was found greater than the conventional Primaquine tab. and Primaquine $15 \mathrm{mg}$ SR tab for 14 day. Adverse effect of primaquine $30 \mathrm{mg} \mathrm{SR}$ tab for 7 days was found lesser than conventional Primaquine tab $15 \mathrm{mg}$ as well as Primaquine $15 \mathrm{mg}$ SR tab.

Conclusions: As Malaria is very prevalent in India which causes significant mortality and morbidity in Indian population. Use of Primaquine $30 \mathrm{mg}$ SR tab has good compliance, efficacy as well as lesser adverse effect.

Keywords: Malaria, P. Vivax, Primaquine SR, Randomized control trial

\section{INTRODUCTION}

Malaria is one of the most important parasitic diseases of human; it remains a major health and economic burden in tropical countries and major cause of death as like HIV and tuberculosis. Mortality and morbidity associated with malaria have a crippling effect on the economies of endemic countries. ${ }^{1}$ it afflicts more than 500 million peoples causing from 1.7 million to 2.5 million death each year. In india $60-65 \%$ of infections are due to P.vivax and $35-40 \%$ are due to P.falciparum Malaria is an acute, recurrent and sometimes chronic vector borne protozoan disease which has worldwide distribution in tropical and subtropical regions. ${ }^{1,2}$

Infection is caused by a parasite of genus Plasmodia which is transmitted to human beings by a pre infected female anophelese mosquito. ${ }^{3}$ Genus Plasmodium has 4 species- $P$. vivax (PV), P. falciparum (PF), P. malariae and $P$. ovale. In India, $P$. vivax and $P$. falciparum are the species commonly found. In spite of worldwide efforts to reduce malaria transmission, it is still the major cause of morbidity and mortality, with overall fatality rate of (10$30 \%$ ) was seen. ${ }^{4}$ The main areas where disease 
predominates are the rural and remote areas, where prompt treatment is not available or not detected in time. ${ }^{5}$

Malaria parasite affects multiple organs of the body like liver, spleen, brain, gastro intestinal tract (G.I.T), gall bladder, pancreas, blood vessels and placenta. So the clinical picture could be wide spectrum ranging from simple malaise to life threatening CNS symptoms like coma. Different organs get involved in various ways like parasitic sequestration in the internal organs, intravascular and immune mediated destruction of RBCs and platelets and cytokine mediated injury. ${ }^{6}$

As the target of malaria parasite is $\mathrm{RBC}$, peripheral blood smear examination is the major diagnostic tool of the disease. Malaria can cause haemostatic abnormalities that range from asymptomatic thrombocytopenia to fulminant disseminated intravascular coagulation (DIC). ${ }^{7}$ Early investigators suggested that the major coagulation abnormality of malaria was DIC, but in recent years clinicians have recognized thrombocytopenia is common and early sign of malaria infection, whereas DIC is rare. It has been estimated that $80 \%$ of patients infected with either $P$. vivax or P.falciparum malaria develop thrombocytopenia during their infection and although the thrombocytopenia is caused by increased platelet destruction, the mechanism has been unknown. ${ }^{9}$

There is no extensive local literature is available on such topic, therefore by keeping and considering such debate in mind the present study was conducted at tertiary care teaching hospital that cover rural as well as urban population and provide all health related emergency facilities.

Primaquine is synthetic antimalarial agent that is 8 aminoquinoline derivative. Primaquine was introduced for treatment of malaria in 1950 when it emerged as a drug of choice for the treatment of exoerythrocytic stage of P.vivax and P.ovale. Primaquine is a major antimalarial agent and highly effective against exoerythrocytic stage of P.vivax and p.ovale and is the best drug for radical cure of relapsing Malaria.it is active against gametocyte of all four plasmodia that infect humans. Because Primaquine is not active against asexual erythrocytic form of plasmodia, a regimen that includes blood schizonticidal agent (eg.chloroquine or quinine) should always be given in conjunction with Primaquine for treatment of P.vivax and P.ovale infection. The exact mechanism of antimalarial activity of Primaquine has not been determined,but the drug appears to be interfere with the function of plasmodial DNA.

At present Primaquine 8-aminoquinoline is the only antimalarial drug available in India for eradication of dormant hepatic stage of P.vivax malaria. The role of Primaquine is well established in the prevention of relapse of P.vivax malaria. Primaquine has a narrow therapeutic range and short half-life that requires daily administration upto 2 weeks, resulting in poor compliance. Primaquine is well absorbed in human GIT and peak concentration in plasma is seen within 2 hours of oral dose. but it is rapidly metabolized with a half life of 6 hours to several metabolites. The activity of these metabolites is considerably less than that of Primaquine itself. Thus Primaquine is well absorbed orally, it has poor bioavailability due to presystemic metabolism and to the enterohepatic circulation it appears to undergo.

Primaquine SR tablets are effective alternative to conventional Primaquine tablets in term of better and prolonged efficacy. Primaquine SR tablet have been developed in $15 \mathrm{mg}$ tablet formulation and $30 \mathrm{mg}$ tablet formulation.The main aim of developing $15 \mathrm{mg}$ SR tablet formulation is to maintain adequate therapeutic concentration in plasma throughout $24 \mathrm{hr}$ and of $30 \mathrm{mg}$ is to reduce therapy from 14 days to 7 days.

With this background we planned a comparative study to evaluate comparative efficacy and safety of Primaquine SR $15 \mathrm{mg}$ and $30 \mathrm{mg}$ tablets vs conventional Primaquine $15 \mathrm{mg}$ tablets in the prevention of relapse of plasmodium vivax Malaria in patient first treated with a standard schizonticidal dose of chloroquine.

\section{METHODS}

This study involved 100 patients of P.vivax Malaria in medical ward of mahatma Gandhi hospital attached to $\mathrm{S}$ $\mathrm{N}$ medical college 'Jodhpur. This study includes patients age group of 18-65yr of both sex having P.vivax malaria.

Other criteria's are:-

- Confirmed case of vivax Malaria by microscopy on a thin and thick smears

- $\quad$ Patient with axillary temp >37.5C; Patient followed up to 6 month

\section{Exclusion criteria}

- $\quad$ Mixed malarial infection

- Patient with body weight less than $40 \mathrm{Kg}$

- Patient with severe and complicated malaria

- Patient with concomitant illness (Cardiac, hepatic, renal disease)

- Patients previously treated with any other antimalarial therapy except chloroquine

- Patients unable to tolerate oral medicine

- Pregnant women and lactating women

- Patient with history of dark urine or significant hemoglobinuria related to Primaquine treatment during the course of previous episode of malaria.

- Patient taking cardioactive drug or potentially hemolytic drug

- $\quad$ Patient with protracted vomiting and oligouria 
- Patient with acute exacerbation of systemic disease having tendency to granulocytopenia eg-rheumatoid arthritis, SLE

- Patient with known history of alcoholism.

- Patient with methemoglobenemia

\section{Efficacy}

Clinical evaluation conducted daily till the patient became asymptomatic and aparasitemic. During hospitalization thick and thin blood smear took twice a day (preferably morning and evening) and axillary body temperature recorded after every 6 hour for 3 days. After discharging the patient follow up done on day-7, day-14, day-21, day-28 and then monthly up to 6 months. Each assessment included review of clinical sign and symptoms, peripheral blood smear examination and body temp. Efficacy is there is no occurrence of microscopically proven P.vivax malaria (asexual form) after treatment with Primaquine. PCR genotyping is done for difference $b / w$ relapse and reinfection.

\section{Safety}

Patient who has received even single tablet evaluated for safety assessment. All adverse events whether previously known with the individual drug or not are recorded. Blood samples are taken for following investigations at the time of hospitalization-Hemogram, TLC, DLC, ESR, Platelet count, blood sugar, S. creatinine, S. bilirubin, SGOT, SGPT, Alkaline phosphatase, Albumin, Globulin, BUN, Urine routine, G6PD, ECG, x-ray.

Patients were followed up on day 7, 14, 21, 28 then monthly up to 6 months. During follow up visit, patient evaluated for clinical sign and symptoms, body temp. measured, thick and thin blood film examined for malaria parasite. Patient with positive blood smear, PCR genotyping was done. Patient advised to return if they are symptomatic at any other time. Initial sample of patient was preserved, if there was relapse of vivax malaria then both sample was sent for PCR genotyping. Patient develop significant intercurrent illness or undergone for surgery removed from study. Patient develops serious adverse effect removed from study.

\section{Dosing and administration}

All patient in this study received chloroquine for 3 days (10mg of base per $\mathrm{kg}$ followed by $5 \mathrm{mg} / \mathrm{kg} \mathrm{6-8}$ hours later and $5 \mathrm{mg} / \mathrm{kg}$ on each of the two days, total $25 \mathrm{mg} / \mathrm{kg}$ over 3days.

Group - 1 Primaquine $15 \mathrm{mg}$ tab $(\mathrm{n}=34)$ for 14 days.

Group - 2 Primaquine 15mg SR tab $(n=33)$ for 14 days.

Group - 3 Primaquine 30mg SR tab $(n=33)$ for 7 days then Placebo for next 7 days.

During screening period patient received oral acetaminophen for temp $>38.4^{0}$ C.If patient fails to respond to chloroquine within 3 days then he is removed from study. Patients are divided into three group. First group was given conventional Primaquine of $15 \mathrm{mg}$ for 14 days. Second group was given Primaquine SR 15mg for 14 days and third group was given Primaquine SR 30 mg for 7 days and placebo tablets for next 7 days. Patient is observed for $>1$ hour after the first dose. If the first dose is vomited then patient was retreated with full dose and if vomiting was persistent then he is removed from study.

\section{RESULTS}

\section{Side effects of different preparation of primaquine}

Chi-square $=1.076$ with 6 degrees of freedom; $\mathrm{P}=0.983$

There is no statistically significant Difference found for any of the above specified Side effect amongst all three groups $(\mathrm{P}>0.05)$. However there are fewer side effects of primaquine $15 \mathrm{mg}$ SR tab then conventional Primaquine $15 \mathrm{mg}$ Tab and Primaquine $30 \mathrm{mg}$ SR tab have fewer side effects than both formulation of Primaquine.

Table 1: Side effects of different preparation of primaquine.

\begin{tabular}{|lllll|}
\hline Drug & $\begin{array}{l}\text { No. of patient of } \\
\text { nausea }\end{array}$ & $\begin{array}{l}\text { No. of patient of } \\
\text { vomiting }\end{array}$ & $\begin{array}{l}\text { No. of patient of } \\
\text { headache }\end{array}$ & $\begin{array}{l}\text { No. of patient of } \\
\text { abdominal pain }\end{array}$ \\
\hline $\begin{array}{l}\text { Conventional } \\
\text { Primaquine Tab. }\end{array}$ & $\begin{array}{l}16 \\
(47.05 \%)\end{array}$ & $6(17.64 \%)$ & $8(23.52 \%)$ & $6(17.64 \%)$ \\
\hline $\begin{array}{l}\text { Primaquine 15mg SR } \\
\text { Tab. }\end{array}$ & $14(42.42 \%)$ & $4(12.12 \%)$ & $6(18.18 \%)$ & $5(15 \% .15)$ \\
\hline $\begin{array}{l}\text { Primaquine 30mg SR } \\
\text { Tab. }\end{array}$ & $14(44.44 \%)$ & $4(12.12 \%)$ & $4(12.12 \%)$ & $3(9.09 \%)$ \\
\hline
\end{tabular}


Table 2: Efficacy of different formulation of tab. primaquine.

\begin{tabular}{|llll|}
\hline & $\begin{array}{l}\text { No } \\
\text { relapse }\end{array}$ & Relapse & Total \\
\hline Primaquine & 29 & 5 & 34 \\
\hline $\begin{array}{l}\text { Primaquine } 15 \\
\text { mg SR }\end{array}$ & 30 & 3 & 33 \\
\hline $\begin{array}{l}\text { Primaquine } 30 \\
\text { mg SR }\end{array}$ & 33 & 0 & 33 \\
\hline
\end{tabular}

\section{Efficacy of different formulation of tab. primaquine}

Chi-square $=5.000$ with 2 degrees of freedom; $\mathrm{P}=0.082$ not significant.

There is no statistically significant Difference found for efficacy amongst all three groups $(\mathrm{P}>0.05)$. However Primaquine $30 \mathrm{mg}$ SR tab do not have any relapse.

Table 3: Compliance of patient with different formulation of tab. primaquine.

\begin{tabular}{|llll|}
\hline & $\begin{array}{l}\text { Treatment } \\
\text { completed }\end{array}$ & $\begin{array}{l}\text { Treatment } \\
\text { not } \\
\text { completed }\end{array}$ & Total \\
\hline Primaquine & 34 & 25 & 59 \\
\hline $\begin{array}{l}\text { Primaquine } \\
15 \text { mg SR }\end{array}$ & 33 & 19 & 52 \\
\hline $\begin{array}{l}\text { Primaquine } \\
30 \text { mg SR }\end{array}$ & 33 & 01 & 34 \\
\hline
\end{tabular}

\section{Compliance of patient with different formulation of tab. primaquine}

Chi-square $=16.817$ with 2 degrees of freedom; $\mathrm{P}=$ 0.000 significant.

There is statistically significant Difference found in compliance of Primaquine $30 \mathrm{mg}$ SR tab. $(\mathrm{P}>0.05)$.

\section{DISCUSSION}

Plasmodium vivax malaria constitutes $60-65 \%$ of total malaria cases in India. Although the infection is benign except for a few case reports of severe malaria, but the morbidity is high especially due to relapses which is characteristic of vivax malaria. Blood schizonticidal drugs are not effective against Persistent hypnozoites of the parasite in the liver. Primaquine (8-aminoquinoline) is the only available drug active against hypnozoites of relapsing malaria parasites.

As per the current national drug policy on malaria microscopically positive PV cases should be treated with chloroquine in full therapeutic dose of $25 \mathrm{mg} / \mathrm{kg}$ body weight divided over 3 days. Primaquine should be given in doses of $0.25 \mathrm{mg} / \mathrm{kg}$ body weight daily for 14 days to prevent relapse except in those with G-6-PD deficiency, infants and pregnant women. To evaluate the efficacy of different dose schedules of chloroquine and or Primaquine, number of studies has been carried out in different geo epidemiological zones of the country where this species of malaria parasite is predominant. However, there is no parasitological and clinical marker available at present which could be used to analyse the genetic diversity of the P. vivax population and correlate this with epidemiological finding. Therefore, there is a strong need for laboratory and field studies as well as the use of mathematical models to interpret the complex transmission dynamics of $\mathrm{P}$. vivax so that appropriate control strategies, including chemotherapeutic measures can be devised.

J. parasitol study in Orrisa with chloroquine alone and chloroquine and 5 day regimen of primaquine. This study suggested that Primaquine regimen with chloroquine had no significant advantage over the use of chloroquine alone. $^{10}$

In our study we found that there was no relapse while using chloroquine plus conventional primaquine or chloroquine plus sustained release primaquine.

Immunity and medicine US army, faculty of tropical medicine, Mahidot University, Bangkok study was on prevention of relapse of P.vivax malaria. In this study tab tafenoquine plus tab chloroquine and tab Primaquine plus tab chloroquine was given for prevention of relapse of P.vivax malaria. In this study there was $98.5 \%$ reduction in relapse of P.vivax with tafenoquine plus chloroquine in compare to chloroquine alone. There was $79.5 \%$ reduction of relapse of P.vivax with Primaquine plus chloroquine in compare with chloroquine alone.

In our study we found that there is no relapse of P.vivax malaria with chloroquine plus Primaquine SR $30 \mathrm{mg}$. So in our study efficacy of this combination is better than above study.

Bunnag D, Karbwang J, Thanavibul A et al study in Thailand, Primaquine $15 \mathrm{mg}$ was used for 14 days ${ }^{11}$, there were relapse of P.vivax because of resistance to Primaquine. Dose of Primaquine was increased to $22.5 \mathrm{mg}$ for 14 days $^{12}$, relapse of P.vivax decreased significantly.

In our study we used high dose Primaquine $30 \mathrm{mg}$ SR it is also useful in preventing relapse of P.vivax in Primaquine resistant malaria.

Department of clinical tropical medicine and hospital, mahidot university, Bangkok, Thailand, conducted a study there was artesunate is given with or without high dose $(0.6 \mathrm{mg} / \mathrm{kg})$ primaquine for prevention of relapse of P.vivax malaria. 50 more patients with artesunate alone developed relapse in compare with artesunate plus Primaquine.31 patients with high dose Primaquine 
developed serious side effect and removed from study because of significant decrease in hematocrit.

In our study patients had not any serious side effects so drop out cases are less and patients' compliance was better than above study.

The role of Primaquine is well established in the prevention of relapse of P.vivax malaria. A study by Trans R Soc Trop Med Hyg. In 2003 to evaluate anti relapse efficacy of a supervised 14 day $15 \mathrm{mg} / \mathrm{d}$ regimen of Primaquine therapy $(n=131)$ compared with no anti relapse therapy $(n=142)$ in 273 patients with confirmed plasmodium vivax malaria in Mumbai, India, between July 1998 and April 2000. There were 6/131 (4.6\%) recurrences in patients given Primaquine compared with $13 / 142(9.2 \%)$ in those not given anti relapse therapy. In our study there is no relapse when anti relapse therapy is given.

\section{CONCLUSION}

In our study patients taking primaquine $30 \mathrm{mgSR}$ had no relapse and only one patient did not complete treatment, so the compliance is better because of reduction of duration of treatment(one week), hense it is beneficial to use primaquine30SR tab.

Using primaquine $30 \mathrm{mg} \mathrm{SR} \mathrm{tab}$, there is greater efficacy and safety in compare with conventional primaquine tab. therefore using primaquine $30 \mathrm{mgSR}$ increases compliance and decreases cost.

Funding: No funding sources Conflict of interest: None declared

Ethical approval: The study was approved by the Institutional Ethical Committee

\section{REFERENCES}

1. Lee GR, Bithel TC, Foerster JA, Athens JW, Leukens JN. Wintrobe's Clinical hematology. 9th ed. London, Lea and Febiges; 1993:198-1201.

2. Mepherson RA, Pincus MR. Blood and Tissue Protozoa, Henry's Clinical Diagnosis and Management by Laboratory Methods, 22nd ed. Elsevier; 2007:1127-34.

3. Park KS. Arthropod born infection, Park's textbook of Preventive and Social Medicine. 15th ed. Jabalpur; 1997:188-202.

4. Kumar AK, Shashirekha PB. Thrombocytopenia- an indication of acute vivax malaria. Indian $\mathrm{J}$ Pathol Microbiol. 2006;49:505-8.

5. Park KS. Arthropod born infection, Park's textbook of Preventive and Social Medicine. 15th ed. Jabalpur; 1997:209-220.

6. Nank NA, Aggraval HM, Sharma MD, Singh MK. Systemic Manifestation of Malaria. J Ind Acad of ClinMed 2007;2(3):189-204.

7. Rodriguez AJ, Morales E, Sanchez M, Vargas C, Piccolo R, Colina M. Clinical infectious disease, 2005:130-131.

8. Sharma SK, Das RK, Das BK, Das P.K. Hematological profile in acute falciparum malaria. J. Assoc. Physicians India. 1992;40:581-3.

9. Kakar A, Bhoi S. Profound thrombocytopenia in plasmodium malaria. Diagn Microbiol Infect Dis. 1999;35:243-.4

10. Gogtay NJ, Desai S, Kamtekar KD, Kadam KD, Dalvy SS, Kshirsagar NA. Efficacy of 5 and 14 day primaquine therepy in prevention of relapse in p.vivax infection. Ann trop med parasitol. 1999;93(8):809-12.

11. Collins WE, Jeffery GN. Primaquine in P.vivax, am J Trop Med Hyg. 1996;55:243-9.

12. Clyde DF. Clinical problems associated with the use of primaquine as a schizonticidal and gamitocidal drug. bull WHO. 1981;59:391-5.

Cite this article as: Gupta VK, Jhalani G, Yadav H, Verma A, Kakkar S. Comparative evaluation of efficacy and safety of primaquine sustained-release tablets v/s primaquine conventional tablets in Treatment and prevention of relapse of plasmodium vivax malaria. Int $\mathrm{J}$ Basic Clin Pharmacol 2016;5:2664-8. 